\title{
Cenário Disfuncional dos Principais Componentes Responsáveis pelo Equilíbrio do Trânsito de Cálcio Miocárdico na Insuficiência Cardíaca Induzida por Estenose Aórtica
}

\author{
The Dysfunctional Scenario of the Major Components Responsible for Myocardial Calcium Balance in Heart \\ Failure Induced by Aortic Stenosis
}

Vitor Loureiro da Silva, ${ }^{1,2}$ Sérgio Luiz Borges de Souza, ${ }^{1}$ Gustavo Augusto Ferreira Mota, ${ }^{10}$ Dijon H. S. Campos, ${ }^{10}$ Alexandre Barroso Melo, ${ }^{3}$ Danielle Fernandes Vileigas, ${ }^{1}$ Paula Grippa Sant'Ana, ${ }^{1}$ Priscila Murucci Coelho, ${ }^{3}$ Silméia Garcia Zanati Bazan, ${ }^{10}$ André Soares Leopoldo, ${ }^{3}{ }^{10}$ Antônio Carlos Cicogna’

Universidade de São Paulo - Departamento de Medicina Interna, ${ }^{1}$ Botucatu, SP - Brasil

Universidade Estadual Paulista - Clínica Médica, ${ }^{2}$ São Paulo, SP - Brasil

Universidade Federal do Espírito Santo - Departamento de Desportos, ${ }^{3}$ Vitória, ES - Brasil

\section{Resumo}

Fundamento: O remodelamento cardíaco patológico se caracteriza por disfunção diastólica e sistólica, levando à insuficiência cardíaca. Neste contexto, o cenário disfuncional do trânsito de cálcio miocárdico $\left(\mathrm{Ca}^{2+}\right)$ tem sido pouco estudado. Um modelo experimental de estenose aórtica tem sido extensamente utilizado para aprimorar os conhecimentos sobre os principais mecanismos do remodelamento patológico cardíaco.

Objetivo: Entender o processo disfuncional dos principais componentes responsáveis pelo equilíbrio do cálcio miocárdico e sua influência sobre a função cardíaca na insuficiência cardíaca induzida pela estenose aórtica.

Métodos: Ratos Wistar de 21 dias de idade foram distribuídos em dois grupos: controle (placebo; $\mathbf{n = 2 8 )}$ e estenose aórtica (EaO; $n=18)$. A função cardíaca foi analisada com o ecocardiograma, músculo papilar isolado e cardiomiócitos isolados. No ensaio do músculo papilar, SERCA2a e a atividade do canal de $\mathrm{Ca}^{2+}$ do tipo $\mathrm{L}$ foram avaliados. $\mathrm{O}$ ensaio de cardiomiócitos isolados avaliou o trânsito de cálcio. A expressão proteica da proteínas do trânsito de cálcio foi analisada com o western blot. Os resultados foram estatisticamente significativos quando $p<0,05$.

Resultados: Os músculos papilares e cardiomiócitos dos corações no grupo EaO demonstraram falhas mecânicas. Os ratos com EaO apresentaram menor tempo de pico do $\mathrm{Ca}^{2+}$, menor sensibilidade das miofibrilas do $\mathrm{Ca}^{2+}$, prejuízos nos processos de entrada e recaptura de cálcio pelo retículo sarcoplasmático, bem como disfunção no canal de cálcio do tipo L (CCTL). Além disso, os animais com EaO apresentaram maior expressão de SERCA2a, CCTL e trocador de $\mathrm{Na}^{+} / \mathrm{Ca}^{2+}$.

Conclusão: Insuficiência cardíaca sistólica e diastólica devido à estenose aórtica supravalvular acarretou comprometimento da entrada de $\mathrm{Ca}^{2+}$ celular e inibição da recaptura de cálcio pelo retículo sarcoplasmático devido à disfunção no CCTL e SERCA2a, assim como mudanças no trânsito de cálcio e na expressão das principais proteínas responsáveis pela homeostase de $\mathrm{Ca}^{2+}$ celular.

Palavras-chave: Estenose da Valva Aórtica; Insuficiência Cardíaca; Músculos Papilares; Miócitos Cardíacos; Proteínas de Ligação ao Cálcio.

\begin{abstract}
Background: Maladaptive cardiac remodelling is characterized by diastolic and systolic dysfunction, culminating in heart failure. In this context, the dysfunctional scenario of cardiac calcium $\left(\mathrm{Ca}^{2+}\right)$ handling has been poorly studied. An experimental model of aortic stenosis has been extensively used to improve knowledge about the key mechanisms of cardiac pathologic remodelling.
\end{abstract}

Objective: To understand the dysfunctional process of the major components responsible for $\mathrm{Ca}^{2+}$ balance and its influence on cardiac function in heart failure induced by aortic stenosis.

Methods: Male 21-day-old Wistar rats were distributed into two groups: control (sham; $n=28$ ) and aortic stenosis (AoS; $n=18)$. Cardiac function was analysed by echocardiogram, isolated papillary muscle, and isolated cardiomyocytes. In the papillary muscle assay, SERCA2a and L-type $\mathrm{Ca}^{2+}$ channel activity was evaluated. The isolated cardiomyocyte assay evaluated $\mathrm{Ca}^{2+}$ handling. $\mathrm{Ca}^{2+}$ handling protein expression was analysed by western blot. Statistical significance was set at $p<0.05$.

Correspondência: Vitor Loureiro da Silva •

Universidade de São Paulo - Departamento de Medicina Interna - Jardim Dona Marta (Rubião Junior), CEP 18618-970, Botucatu, SP - Brasil E-mail: vitorloureiro_ed.fisica@hotmail.com

Artigo recebido em 08/06/2020, revisado em 26/01/2021, aceito em 24/02/2021

DOI: https://doi.org/10.36660/abc.20200618 
Results: Papillary muscles and cardiomyocytes from AoS hearts displayed mechanical malfunction. AoS rats presented a slower time to the Ca ${ }^{2+}$ peak, reduced $\mathrm{Ca}^{2+}$ myofilament sensitivity, impaired sarcoplasmic reticulum Ca ${ }^{2+}$ influx and reuptake ability, and SERCA2a and L-type calcium channel (LTCC) dysfunction. Moreover, AoS animals presented increased expression of SERCA2a, LTCCS, and the $\mathrm{Na}^{+} / \mathrm{Ca}^{2+}$ exchanger.

Conclusion: Systolic and diastolic heart failure due to supravalvular aortic stenosis was paralleled by impairment of cellular Ca influx and inhibition of sarcoplasmic reticulum $\mathrm{Ca}^{2+}$ reuptake due to LTCC and SERCA2a dysfunction, as well as changes in $\mathrm{Ca}^{2+}$ handling and expression of the major proteins responsible for cellular $\mathrm{Ca}^{2+}$ homeostasis.

Keywords: aortic stenosis; heart failure; papillary muscle; isolated cardiomyocytes; calcium handling proteins.

Full texts in English - https://abccardiol.org/en/

\section{Introdução}

A insuficiência cardíaca (IC) se caracteriza pela incapacidade do coração de realizar a perfusão de tecidos com o oxigênio e os nutrientes requeridos pela demanda metabólica do corpo; ${ }^{1}$ importantes desfechos intolerância ao esforço e retenção hídrica. ${ }^{2} \mathrm{O}$ processo da IC é produto do remodelamento mal adaptado, que pode ocorrer devido a vários tipos de dano no coração, incluindo isquemia miocárdica e sobrecarga de volume e pressão. ${ }^{3}$ Entre outros, o prejuízo do trânsito de cálcio é um mecanismo crucial da deterioração progressiva da função contrátil na IC. ${ }^{4}$

Pesquisadores reportaram mudanças na expressão e na função de proteínas reguladoras do trânsito de cálcio em várias doenças cardiovasculares. ${ }^{5-23}$ No remodelamento patológico induzido pela estenose aórtica, estudos identificaram, por meio de diferentes métodos de indução cirúrgica e períodos da doença, várias mudanças nos elementos reguladores do $\mathrm{Ca}^{2+} .{ }^{11,12,14-22}$ Estudos iniciais sugeriram que mudanças na saída e na entrada do retículo sarcoplasmático de $\mathrm{Ca}^{2+}$ estão relacionadas à disfunção cardíaca causada pela estenose aórtica. ${ }^{11,12}$ Nossos estudos anteriores avaliaram ratos com disfunção diastólica após seis e doze semanas da estenose aórtica. ${ }^{16,17}$ Após seis semanas, observou-se uma deficiência na atividade do cálcio ATPase (SERCA2a) do retículo endo/sarcoplasmático sem alteração na expressão da proteína; ${ }^{16}$ após doze semanas, observou-se um aumento na fosforilação do resíduo Ser(16) da PLB e menor expressão da proteína SERCA2a. ${ }^{17}$ Além disso, em animais com IC após obstrução da aorta, ${ }^{19,21,24}$ os autores detectaram corrente de $\mathrm{Ca}^{2+}\left(\mathrm{I}_{\mathrm{Ca}}\right)$ reduzida, ineficiência do acoplamento dos canais de cálcio do tipo L (CCTL) com os receptores Rianodina, ${ }^{20}$ e mudanças nas proteínas de trânsito de cálcio. ${ }^{19-22}$

Como as investigações demonstram dados diferentes relacionados ao nível estrutural e funcional do remodelamento cardíaco e as adaptações correspondentes à dinâmica do $\mathrm{Ca}^{2+}$ do miocárdio, este estudo teve como objetivo caracterizar o processo disfuncional dos principais responsáveis pelo equilíbrio do $\mathrm{Ca}^{2+}$ e sua influência na função cardíaca da IC induzida por estenose aórtica. Para este fim, diferentemente de estudos anteriores, realizamos uma avaliação cardíaca global de animais 28 semanas após a estenose aórtica. Este estudo analisou a função cardíaca nos níveis celular, tecidual e de câmara, e também examinou o trânsito de cálcio e proteínas responsáveis pelo equilíbrio do $\mathrm{Ca}^{2+}$ citosólico, apresentando resultados divergentes e surpreendentes em comparação ao que hoje está disponível na literatura.

\section{Métodos}

\section{Desenho do estudo}

Um grupo de ratos machos Wistar, de 21 dias de idade, foi submetido à cirurgia de indução simulada (placebo, $n=22$ ) ou de estenose aórtica $(\mathrm{EaO}, \mathrm{n}=12)$. Vinte e oito semanas após o protocolo experimental, a função cardíaca foi avaliada por ecocardiograma e músculo papilar isolado. A atividade da SERCA2a e do CCTL foi analisada durante a potenciação pós-pausa e elevação do cálcio, respectivamente, e pela administração cumulativa do $\mathrm{CA}^{2+}$ extracelular na presença de bloqueadores específicos de SERCA2a ou CCTL no ensaio do músculo papilar isolado. A expressão das proteínas reguladoras de trânsito de cálcio foi medida pelo western blot (placebo, $\mathrm{n}=7 ; \mathrm{EaO}, \mathrm{n}=7$ ). Cinco animais com $\mathrm{EaO}$ foram excluídos do experimento do músculo papilar isolado por terem uma área transversal do músculo papilar maior do que $1,5 \mathrm{~mm}^{2}$.

Outro grupo de ratos machos Wistar foi submetido à cirurgia de indução simulada (placebo, $n=6$ ) ou de estenose aórtica (EaO, n=6). Nesses animais, o eletrocardiograma foi realizado e os cardiomiócitos foram isolados. Uma análise dos cardiomiócitos isolados foi realizada para avaliar a função mecânica dos cardiomiócitos e o manejo do cálcio.

Como observado, a avaliação do ecocardiograma foi realizada em todos os animais (placebo, $\mathrm{n}=28$; $\mathrm{EaO}, \mathrm{n}=18$ ).

\section{Animais}

Ratos Wistar obtidos do Centro Animal da Faculdade de Medicina de Botucatu (Botucatu, São Paulo, Brasil) foram inseridos em gaiolas coletivas a $23^{\circ} \mathrm{C}$, temperatura ambiente, em um ciclo claro-escuro de 12 horas, umidade relativa de $60 \%$ e água ad libitum. Esta pesquisa foi aprovada pelo Comitê de Ética em Pesquisa Experimental da Faculdade de Medicina de Botucatu - UNESP", e pelo "Guia para o cuidado e uso de animais de laboratório" (protocolo 1138/2015).

\section{Cirurgia de estenose aórtica}

A EaO foi induzida cirurgicamente, como já descrito. ${ }^{14-17}$ Os ratos foram anestesiados com uma mistura de cetamina (50 $\mathrm{mg} / \mathrm{kg}$, IM) e xilazina (1 mg/kg, IM), e o coração foi exposto por meio de uma toracotomia mediana. Um clip de prata $(0,62$ $\mathrm{mm}$ de diâmetro interno) foi colocado na aorta ascendente, a aproximadamente $3 \mathrm{~mm}$ de sua raiz, constituindo o grupo $\mathrm{EaO}(\mathrm{n}=17)$. Os ratos controle foram submetidos à mesma cirurgia, porém, sem a bandagem da aorta (placebo, $n=19$ ). 


\section{Função cardíaca}

\section{Ecocardiograma}

Dados da estrutura cardíaca e análise de função estão expressos com variáveis do ecocardiograma 28 semanas após a estenose aórtica. Uma ecocardiografia disponível no mercado (General Electric Medical Systems, Vivid S6, Tirat Carmel, Israel), equipada com uma sonda multifrequência de 5-11,5 $\mathrm{MHz}$, foi utilizada, como descrito anteriormente. ${ }^{17,25,26}$ Os ratos foram anestesiados por meio de uma injeção intraperitoneal, com uma mistura de cetamina $(50 \mathrm{mg} / \mathrm{kg})$ e xilazina $(0,5$ $\mathrm{mg} / \mathrm{kg}$ ). As seguintes variáveis foram utilizadas para avaliar a estrutura cardíaca: átrio esquerdo (AE) normalizado para o diâmetro da aorta $(\mathrm{AE} / \mathrm{Ao})$, diâmetro diastólico do ventrículo esquerdo (DDVE), diâmetro sistólico do ventrículo esquerdo (DSVE), espessura diastólica da parede posterior (EDPP), espessura diastólica do septo interventricular (EDSI) e espessura relativa da parede (ERP). Os seguintes parâmetros foram usados para avaliar a função ventricular: frequência cardíaca (FC), fração de encurtamento da parede média (FS); fração de ejeção (FE); velocidade sistólica da parede posterior (VSPP), velocidade de influxo mitral diastólico precoce (onda E); e pico de velocidade da onda A (contração atrial), velocidade anular mitral durante o enchimento ventricular precoce $\left(E^{\prime}\right)$, velocidade anular mitral durante a contração atrial $\left(A^{\prime}\right)$, e razão entre o fluxo de pico do enchimento e a velocidade anular mitral durante o enchimento ventricular precoce $\left(E / E^{\prime}\right)$.

\section{Sinais da insuficiência cardíaca}

O mesmo investigador analisou os sinais clínicos e patológicos da IC (taquipneia, ascite, efusão pleural, trombo em átrio esquerdo e hipertrofia ventricular direita), sem acesso aos grupos experimentais.

\section{Ensaio isolado do músculo papilar}

O desempenho contrátil do coração foi avaliado ao examinar os músculos papilares isolados do ventrículo esquerdo (VE), como descrito anteriormente. ${ }^{14,17,25}$ Os músculos papilares foram estimulados 12 vezes por minuto $(0,2 \mathrm{~Hz})$, utilizando eletrodos do tipo agulha de platina posicionados paralelamente ao eixo longitudinal dos músculos. Os eletrodos foram acoplados a um estimulador elétrico (LE12406 - Stimulator, PanLab - Harvard Apparatus, Cornella, Barcelona, Espanha) que emite estímulos de onda quadrada de $5 \mathrm{~ms}$. A voltagem do estímulo utilizado foi de 12 a 15 volts, aproximadamente $10 \%$ acima do valor mínimo necessário para provocar a resposta mecânica máxima do músculo. No experimento, a solução de Krebs-Henseleit foi utilizada de acordo com a seguinte composição em $\mathrm{mM}$ : $118,5 \mathrm{NaCl} ; 4,69 \mathrm{KCl} ; 2,5 \mathrm{CaCl}_{2} ; 1,16 \mathrm{MgSO}_{4} ; 1,18 \mathrm{KH}_{2} \mathrm{PO}_{4}$; 5,50 de glicose e 24,88 $\mathrm{NaHCO}_{3}$. A solução foi aerada por 10 minutos com oxigênio a $95 \%\left(\mathrm{O}_{2}\right)$ e dióxido de carbono a $5 \%\left(\mathrm{CO}_{2}\right)$, e mantida a $28^{\circ} \mathrm{C}$. Os seguintes parâmetros mecânicos foram medidos durante a contração isométrica: pico de tensão desenvolvida (TD; $\mathrm{g} / \mathrm{mm}^{2}$ ), tensão em repouso (TR; g/mm2), taxa máxima da tensão desenvolvida ( $+\mathrm{tD} / \mathrm{td}$; $\mathrm{g} / \mathrm{mm}^{2} / \mathrm{s}$ ) e declínio (-tD/td; $\left.\mathrm{g} / \mathrm{mm}^{2} / \mathrm{s}\right)$, e tempo de pico de tensão (TPT; ms). Mecanismos reguladores da entrada de $\mathrm{Ca}^{2+}$ e a atividade do CCTL foram analisados pela manobra de elevação da concentração extracelular de $\mathrm{Ca}^{2+}$, e elevação das concentrações extracelulares de $\mathrm{Ca}^{2+}(0,5,1,5,2,5$ e $3,5 \mathrm{mM})$ na presença e na ausência de diltiazem $\left(10^{-5} \mathrm{M}\right)$, um bloqueador específico dos CCTL. Uma manobra de potenciação pós-pausa (o estímulo foi pausado por 10, 30 e $60 \mathrm{~s}$ antes de reiniciar a estimulação) e uma elevação das concentrações extracelulares de $\mathrm{Ca}^{2+}(0,5,1,5,2,5$, e 3,5 mM) na presença e na ausência do ácido ciclopiazônico (CPA, 30 $\mathrm{mM}$ ), um bloqueador altamente específico de SERCA2a, foram realizadas para avaliar o potencial da função de SERCA2a. Os ensaios do bloqueio dos CCTL e SERCA2a foram avaliados com base na porcentagem de inibição, calculada como $\Delta(\%)=(M 2-M 1) / M 1 \times 100$, de forma que M1 é o valor da variável na concentração extracelular de cálcio, na ausência do bloqueador, e M2 é o valor da mesma variável em resposta aos bloqueadores. Testes de elevação extracelular do cálcio e potenciação pós-pausa foram analisados pelo percentual de resposta comparado à linha de base, calculada como $\Delta(\%)=$ $(M 0-M x) / M 0 \times 100$, de forma que M0 é o valor na condição de base, e $M x$ é o valor absoluto em resposta à manobra (concentração aumentada de cálcio ou paralisia do estímulo elétrico). Todas as variáveis foram normalizadas por área transversal do músculo papilar. Os músculos papilares com área transversal $>1,5 \mathrm{~mm}^{2}$ foram excluídos da análise porque podem demonstrar hipóxia central e desempenho funcional prejudicado. ${ }^{16,17}$

\section{Ensaio de cardiomiócitos isolados}

\section{Preparação dos cardiomiócitos}

Sob anestesia, ratos de cada grupo foram eutanasiados. Os corações foram rapidamente removidos por toracotomia e isolados enzimaticamente, como descrito anteriormente. ${ }^{27}$ Brevemente, os corações foram canulados. A perfusão retrógrada da aorta foi realizada em um sistema Lagendorff $\left(37^{\circ} \mathrm{C}\right)$, com solução tampão de digestão (TD) e isolamento modificada, uma solução livre de cálcio contendo $0,1 \mathrm{mM}$ de etilenoglicol bis (ß-álcool aminoetílico)-N, N, N', ácido $\mathrm{N}^{\prime}$-tetracético (EGTA), e $\mathrm{N}$-[2-hidroxietil piperazina- $\mathrm{N}^{\prime}$ [ácido 2- etanosulfónico)] (HEPES), que foram equilibradas. A composição da solução do TD foi a seguinte $(\mathrm{mM}): 130 \mathrm{NaCl}$, 1,4 $\mathrm{MgCl}_{2}$, 5,4 KCl, 25 HEPES, 22 de glicose, 0,33 $\mathrm{NAH}_{2} \mathrm{PO} 4$ e pH 7.39. Depois, os corações foram perfundidos por 15-20 minutos, com solução TD contendo $1 \mathrm{mg} / \mathrm{ml}$ de colagenase tipo II (Worthington Biochemical Corporation, Reino Unido) e $\mathrm{Ca}^{2+}(1 \mathrm{mM})$. Após a digestão, os corações foram removidos da cânula, cortados em pequenos pedaços e colocados em frascos cônicos com solução TD contendo colagenase suplementada com $0,1 \%$ de albumina de soro bovino e $\mathrm{Ca}^{2+}$ (1 mM). Em seguida, este processo foi realizado mais duas vezes sem a colagenase e com a adição de 1,6 e 3,12 $\mu \mathrm{L}$ de $1,0 \mathrm{mM}$ da solução padrão $\mathrm{CaCl}_{2}$. Cada etapa contendo células e soluções foi incubada por aproximadamente 10 minutos. Então, o sobrenadante foi removido e os miócitos foram suspendidos novamente em solução de Tyrode contendo o seguinte (em mM): $140 \mathrm{NaCl}, 10$ HEPES, 0,33 
$\mathrm{NaH}_{2} \mathrm{PO}_{4}, 1 \mathrm{MgCl}_{2}, 5 \mathrm{KCl}, 1,8 \mathrm{CaCl}_{2}, 10$ de glicose. Somente cardiomiócitos tolerantes ao cálcio, quiescentes, em formato de haste, mostrando estriações transversais claras, foram examinados. Os cardiomiócitos isolados foram utilizados após 2 a 3 horas de isolamento.

\section{Contratilidade em cardiomiócitos}

De forma breve, células isoladas foram colocadas em uma câmara experimental com uma base de lamelas montada na mesa de um microscópio invertido (Ion Optix, Milton, MA, EUA), com sistema de detecção de bordas e lentes objetivas 40x (Nikon Eclipse - TS100, EUA). As células foram imersas em solução de Tyrode e o campo foi estimulado a $1 \mathrm{~Hz}(20$ $\mathrm{V}, 5 \mathrm{~ms}$ de duração dos pulsos quadrados). O encurtamento das células em resposta ao estímulo elétrico foi mensurado por meio de um sistema de detecção de bordas em vídeo, com taxa de frames de 240-Hz (lonwizard, Ion Optix, Milton, MA, EUA), e os parâmetros de contração foram avaliados. O comprimento do sarcômero, o encurtamento fracional (expresso como uma porcentagem do comprimento da célula em repouso), velocidade máxima de encurtamento (VME), velocidade máxima de relaxamento (VMR), assim como tempo até o encurtamento de 50\% (tempo para pico de 50\%), e tempo até o relaxamento de $50 \%$ (tempo para relaxamento de $50 \%$ ) foram medidos em seis células por animal em cada grupo experimental.

\section{Medidas de $\mathrm{Ca} 2+$ intracelular}

Em seguida, os cardiomiócitos foram estimulados a $1 \mathrm{~Hz}$ (Myopacer 100, Ion Optix Inc.), e as imagens fluorescentes foram obtidas com comprimento de onda de excitação alternando de 340 a 380 nm, utilizando um sistema Hyper Switch (lonOptix, Milton, MA). A emissão de fluorescência com subtração de background foi obtida, e a razão de Fura 2 AM foi utilizada como índice de transiente intracelular de $\left[\mathrm{Ca}^{2+} \mathrm{i}\right.$, detectado em aproximadamente $510 \mathrm{~nm}$. A amplitude do transiente de $\mathrm{Ca}^{2+}$ foi reportada como F/FO. F é a media de intensidade de fluorescência máxima medida no pico dos transientes de [Ca $\left.{ }^{2+}\right]$ i, e F0 é a intensidade base de fluorescência medida na fase diastólica dos transientes de $\left[\mathrm{Ca}^{2+}{ }^{2}\right.$ i. O tempo para o pico de $\left[\mathrm{Ca}^{2+}\right]$ e o tempo para a queda de $50 \%$ do $\mathrm{Ca}^{2+}$ também foram analisados.

\section{Expressão das proteínas do trânsito de cálcio}

A análise western blot foi usada para avaliar a expressão da proteína dos componentes reguladores do manejo do $\mathrm{Ca}^{2+}$. Fragmentos do VE foram congelados em nitrogênio líquido e armazenados a $-80^{\circ} \mathrm{C}$. Amostras congeladas foram, então, homogeneizadas em tampão RIPA contendo inibidores de protease (Sigma-Aldrich, St. Louis, MO, EUA) e fosfatase (Roche Diagnostics, Indianápolis, IN, EUA), utilizando um homogeneizador bead beater (Bullet Blender ${ }^{\circledR}$, Next Advance, Inc., NY, EUA). O produto homogeneizado foi centrifugado (5804R Eppendorf, Hamburgo, Alemanha) a 12.000 rpm por 20 minutos, a $4^{\circ} \mathrm{C}$, e o sobrenadante foi transferido para tubos Eppendorf e armazenado a $-80^{\circ} \mathrm{C}$. A concentração de proteína foi determinada utilizando um kit de ensaio da proteína BCA (Pierce). A SDS-PAGE foi usada para dissolver novamente um total de $25 \mu$ g de lisado de proteína de cada amostra. A eletroforese foi realizada com gel de empilhamento bifásico (240 mm Tris-HCl pH 6,8, 30\% poliacrilamida, APS e TEMED) e redissolvida (240 mm Tris- $\mathrm{HCl}$ pH 8,8, 30\% poliacrilamida, APS e TEMED) a uma concentração de 6 a $10 \%$, dependendo do peso molecular da proteína analisada. O Kaleidoscope Prestained Standard (Bio-Rad, Hercules, CA, EUA) foi usado para identificar o tamanho das bandas. A eletroforese foi realizada a $120 \mathrm{~V}$ (Power Pac HC 3.0 A, BioRad, Hercules, CA, EUA) por 3 horas, com tampão (0.25 M Tris, $192 \mathrm{mM}$ glicna, e 1\% SDS). As proteínas foram transferidas para uma membrana de nitrocelulose (Armsham Biosciences, Piscataway, NJ, EUA), usando um sistema de mini trans-blot (Bio-Rad, Hercules, CA, EUA) com tampão de transferência (25 mM Tris, 192 mM glicina, 20\% metanol e 0,1\% SDS). As membranas foram bloqueadas com $5 \%$ de leite em pó desnatado em tampão TBS-T (20 mM Tris-HCl pH 7,4, 137 $\mathrm{mM} \mathrm{NaCl} \mathrm{e} \mathrm{0,1 \%} \mathrm{Tween} \mathrm{20)} \mathrm{por} 120$ minutos, em temperatura ambiente, sob constante agitação. A membrana foi lavada três vezes com TBS-T e incubada por 12 horas a $4-8{ }^{\circ} \mathrm{C}$ sob constante agitação, com os seguintes anticorpos primários: Serca2 ATPase (1:2500; ABR, Affinity BioReagents, Golden, CO, EUA), Fosfolambam (1:5000; ABR), Fosfo-Fosfolambam (Ser16) (1:5000; Badrilla, Leeds, West Yorkshire, Reino Unido), Fosfo-Fosfolambam (Thr17) (1:5000; Badrilla), Exchanger $\mathrm{Na}^{+} / \mathrm{Ca}^{2+}$ (1:2000; Upstate, Lake Placid, NY, EUA), Canal de Cálcio, Voltagem Alfa 1C (1:100; Chemicon International, Temecula, CA, EUA), Receptor de Rianodina (1:5000; ABR, Affinity Bioreagents, Golden, CO, EUA) e GAPDH (1:1000; Santa Cruz Biotechonology Inc., CA, EUA). Após a incubação com o anticorpo primário, as membranas foram lavadas três vezes em TBS-T e incubadas com anticorpos secundários conjugados com peroxidase (IgG anti-coelho ou anti-rato; 1: 5.000- 1: 10.000; Abcam) por 2 horas sob constante agitação. As membranas, então, foram lavadas três vezes com TBS-T para remover o excesso dos anticorpos secundários. Os blots foram incubados com ECL (Enhanced Chemi-Luminescence, Amersham Biosciences, Piscataway, Nova Jersey) para detecção da quimioluminescência pela ImageQuant ${ }^{\text {TM }}$ LAS 4000 (GE Healthcare). A análise quantitativa dos blots foi realizada com o software Scion Image (Scion Corporation, Frederick, MD, EUA). Os imunoblots foram quantificados por densitometria utilizando o software ImageJ Analysis (NIH), e os resultados da banda alvo foram normalizados para a expressão do GAPDH do coração. ${ }^{14}$ Não foi possível analisar o GAPDH (37 kDa) como normalizador no mesmo gel que o receptor de rianodina $(565 \mathrm{kDa})$ devido à diferença no peso molecular entre as duas proteínas. Por isso, o receptor de rianodina é expresso sem normalização.

\section{Análise estatística}

A análise estatística foi realizada com o software Sigma Stat 3.5 (SYSTAT Software Inc., San Jose, CA, EUA). A distribuição das variáveis foi avaliada utilizando o teste de KolmogorovSmirnov para normalidade. De acordo com os dados de normalidade, os resultados são reportados como média \pm desvio padrão (DP) ou mediana (percentil 25; percentil 75). As comparações entre os grupos foram realizadas com o teste t de Student bicaudal para amostras independentes, ou o teste te Mann-Whitney ou a análise variância com dois fatores de 
medidas repetidas (ANOVA), quando apropriado. O nível de significância foi considerado quando $5 \%$.

O tamanho da amostra ( $n$ ) foi estimado utilizando a equação para comparação entre grupos: $n=2 \mathrm{SD} 2(Z \alpha / 2$ $+Z \beta) 2 / d$, no qual n é o tamanho da amostra, $D P=0,02$ de estudos anteriores, $Z \alpha / 2=1,96$ (da tabela $Z$ ) com erro tipo 1 de $5 \%, Z \beta=0,842$ (da tabela $Z$ ) com poder de $80 \%$ e = 0,02 (efeito do tamanho - diferença mínima entre os valores médios). ${ }^{28} \mathrm{O}$ tamanho da amostra necessário para detectar uma diferença significativa entre os grupos foi de 16 ratos por grupo; porém, decidimos usar 22 animais com simulação (placebo) e 18 induções de estenose aórtica (EaO) por grupo para o desenho do estudo.

\section{Resultados}

Avaliação do ecocardiograma e sinais de insuficência cardíaca

Os dados do ecocardiograma revelaram que a estenose aórtica resultou predominantemente em hipertrofia cardíaca concêntrica ( $\uparrow E R P, \uparrow E D P P, \uparrow E D S I$, e $\uparrow D D V E$ ), dilatação do átrio esquerdo ( $\uparrow \mathrm{AE} / \mathrm{Ao}$ ) e disfunção diastólica ( $\uparrow$ onda $\mathrm{E}, \uparrow \mathrm{E} / \mathrm{A}$, $\uparrow E / E^{\prime}, \downarrow E^{\prime}$, e $\downarrow A^{\prime}$ ) e sistólica ( $\uparrow \mathrm{DSVE}, \downarrow V E P P, \downarrow F S$ e $\left.\downarrow F E\right) 28$ semanas após a cirurgia (Tabela 1). Os seguintes sinais clínicos e patológicos da IC foram detectados: ascite (30\%), trombo em átrio esquerdo (48\%), efusão pleural (68\%), taquipneia (79\%) e hipertrofia ventricular direita (100\%) (Tabela 1).

\section{Avaliação isolada do músculo papilar}

\section{Dados de base}

A estenose aórtica prejudicou as funções de contração e relaxamento do miocárdio ao reduzir a tensão desenvolvida e a taxa máxima de tensão desenvolvida, e ao aumentar a tensão de repouso e o tempo do pico de tensão (Tabela 2).

\section{Manobras do músculo papilar isolado}

A Figura 1A-C apresenta a porcentagem de resposta do músculo papilar à potenciação pós-pausa (10, 30 e 60 s). Animais com estenose aórtica apresentaram pouca resposta à manobra de potenciação pós-pausa em comparação aos animais no placebo

Tabela 1 - Dados do ecocardiograma e sinais de insuficiência cardíaca

\begin{tabular}{|c|c|c|c|}
\hline & Placebo & $\mathrm{EaO}$ & Valor de $p$ \\
\hline $\mathrm{FC}(\mathrm{bpm})$ & $302 \pm 40$ & $298 \pm 40$ & 0,857 \\
\hline DDVE $(\mathrm{mm})^{*}$ & $7,55(7,15 ; 7,66)$ & $8,43(7,27 ; 9,20)$ & $<0,001$ \\
\hline DSVE $(\mathrm{mm})^{*}$ & $3,20(2,81 ; 3,32)$ & $3,83(3,32 ; 5,62)$ & $<0,001$ \\
\hline $\operatorname{EDPP}(\mathrm{mm})^{*}$ & $1,53(1,53 ; 1,65)$ & $2,81(2,55 ; 3,07)$ & $<0,001$ \\
\hline $\mathrm{EDSI}(\mathrm{mm})^{*}$ & $1,65(1,53 ; 1,70)$ & $3,07(2,84 ; 3,26)$ & $<0,001$ \\
\hline ERP & $0,43 \pm 0,03$ & $0,69 \pm 0,16$ & $<0,001$ \\
\hline $\mathrm{AE} / \mathrm{Ao}$ & $1,22 \pm 0,09$ & $1,91 \pm 0,18$ & $<0,001$ \\
\hline Onda $\mathrm{E}(\mathrm{cm} / \mathrm{s})$ & $85 \pm 7$ & $132 \pm 18$ & $<0,001$ \\
\hline$E / A$ & $1,49 \pm 0,18$ & $5,13 \pm 1,40$ & $<0,001$ \\
\hline $\mathrm{E}^{\prime}(\mathrm{cm} / \mathrm{s})$ & $6,20 \pm 0,78$ & $5,32 \pm 0,89$ & $<0,001$ \\
\hline$A^{\prime}(\mathrm{cm} / \mathrm{s})$ & $4,28 \pm 0,67$ & $3,12 \pm 1,18$ & $<0,001$ \\
\hline $\mathrm{E} / \mathrm{E}^{\prime}$ & $13,9 \pm 2,22$ & $25,2 \pm 4,66$ & $<0,001$ \\
\hline $\operatorname{VSPP}(\mathrm{cm} / \mathrm{s})$ & $68 \pm 9$ & $37 \pm 9$ & $<0,001$ \\
\hline FS (\%) & $26,1 \pm 3,42$ & $23,3 \pm 4,69$ & 0,028 \\
\hline FE $(\%)^{*}$ & $93(92 ; 94)$ & $89(79 ; 92)$ & $<0,001$ \\
\hline Ascite (\%) & 0 & 30 & - \\
\hline TAE (\%) & 0 & 48 & - \\
\hline EP (\%) & 0 & 68 & - \\
\hline Taquipneia (\%) & 0 & 79 & - \\
\hline HVD (\%) & 0 & 100 & - \\
\hline
\end{tabular}

Dados são expressos em média $\pm D P$ ou mediana (percentil 25; percentil 75$)$. Placebo: animais submetidos à cirurgia simulada ( $n=28$ ); EaO: animais submetidos à cirurgia de estenose aórtica ( $n=18$ ). FC: frequência cardíaca; DDVE: diâmetro diastólico do ventrículo esquerdo; DSVE: diâmetro sistólico do ventrículo esquerdo; EDPP: espessura diastólica da parede posterior; EDSI: espessura diastólica do septo interventricular; ERP: espessura relativa da parede no ventrículo esquerdo; AE: átrio esquerdo; AO: diâmetro da aorta; E/A: razão entre o pico de fluxo de enchimento (onda E) e pico de fluxo da contração atrial (onda A); FE: fração de ejeção; FS: fração de encurtamento da parede média; VSPP: velocidade sistólica da parede posterior; E': velocidade anular mitral durante o enchimento ventricular precoce; A': velocidade anular mitral durante a contração atrial; E/E': razão entre o pico de fluxo do enchimento e a velocidade anular mitral durante o enchimento ventricular precoce. TAE: trombo em átrio esquerdo; EP: efusão pleural; HVD: hipertrofia ventricular direita. Teste $t$ de Student ou teste de Mann-Whitney. ${ }^{*} p<0,05$. 
Tabela 2 - Dados de base

\begin{tabular}{lccc}
\hline & Placebo & Ea0 & Valor de p \\
\hline ATV $\left(\mathrm{mm}^{2}\right)$ & $1,15 \pm 0,16$ & $1,18 \pm 0,20$ & 0,589 \\
\hline TD $\left(\mathrm{g} / \mathrm{mm}^{2}\right)$ & $6,26 \pm 1,58$ & $5,18 \pm 0,93$ & 0,039 \\
\hline TR $\left(\mathrm{g} / \mathrm{mm}^{2}\right)$ & $0,60 \pm 0,20$ & $0,80 \pm 0,24$ & 0,010 \\
\hline$+\mathrm{tD} / \mathrm{td}\left(\mathrm{g} / \mathrm{mm}^{2} / \mathrm{s}\right)$ & $66,6 \pm 17,7$ & $46,9 \pm 10,3$ & 0,001 \\
\hline tD $/ \mathrm{td}\left(\mathrm{g} / \mathrm{mm}^{2} / \mathrm{s}\right)$ & $22,1 \pm 5,24$ & $23,9 \pm 5,40$ & 0,346 \\
\hline TPT $(\mathrm{ms})^{\#}$ & $180(180 ; 185)$ & $200(180 ; 217)$ \\
\hline
\end{tabular}

Os dados são expressos como média \pm DP ou mediana (percentil 25; percentil 75)\#. Placebo: animais submetidos à cirurgia simulada ( $n=22) ;$ EaO: animais submetidos à cirurgia de estenose aórtica $(n=12)$. ATV: área transversal papilar; TD: pico de tensão desenvolvida; TR: tensão de repouso; $+t D / t d$ : taxa máxima de tensão desenvolvida; -tD/td: taxa máxima do declínio da tensão; TPT: tempo de pico de tensão. Teste $t$ de Student ou teste de Mann-Whitney. $p<0,05$

para todos os períodos e variáveis avaliados. Não houve diferença significativa entre os grupos em nenhum período. A Figura 1D-F apresenta a porcentagem de resposta do músculo papilar para aumentar a concentração de cálcio extracelular $(1,5 ; 2 ; 5$ e 3,5 $\mathrm{mM})$. A Figura $2 \mathrm{~A}-\mathrm{C}$ mostra as respostas do músculo papilar à inibição de SERCA2a e um aumento na concentração de cálcio. Após a inibição de SERCA2a pelo ácido ciclopiazônico, houve diferença significativa entre os grupos na concentração de cálcio a 0,5 mM para o pico de tensão desenvolvida (Figura 2A). A taxa máxima de tensão desenvolvida e de declínio não demonstraram diferença entre os grupos EaO e placebo. A Figura 2D-F apresenta a resposta do músculo papilar à inibição do canal de cálcio tipo $\mathrm{L}$, mostrando um aumento na concentração de cálcio. Animais com estenose aórtica tiveram pior desempenho na resposta à elevação do cálcio após o bloqueio do CCTL em comparação aos animais do placebo para todos os períodos e variáveis avaliados.

\section{Cardiomiócitos isolados}

\section{Função mecânica e análise do manejo do cálcio}

A Figura 3A-F mostra a função mecânica dos cardiomiócitos. A estenose aórtica afetou a VME (Figura 3B) e os tempos para alcançar 50\% de contração dos cardiomiócitos (Figura 3E) e o pico de relaxamento (Figura 3F). A Figura 3G-J resume trânsito de cálcio 28 semanas após a estenose aórtica. Os animais com EaO apresentaram alterações nos tempos para alcançar o pico do $\mathrm{Ca}^{2+}$ e a queda de $50 \%$ de $\mathrm{Ca}^{2+}$.

\section{Expressão das proteínas do trânsito de cálcio}

Os dados relacionados à expressão proteica dos elementos reguladores do trânsito de cálcio são demonstrados na Figura 4AE. A estenose aórtica aumentou o CCTL, SERCA2a e a proteína de expressão do antiportador $\mathrm{Na}^{+} / \mathrm{Ca}^{2+}$, e reduziu a fosforilação no resíduo $\mathrm{Thr}(17)$ da fosfolambam fosforilada (PLB).

\section{Discussão}

No modelo experimental da estenose aórtica supravalvular, estudos investigando o remodelamento patológico e a insuficiência cardíaca, com foco em alterações específicas do trânsito de cálcio e seus elementos reguladores, apresentaram dados escassos e uma reflexão superficial sobre os mecanismos. Assim, este trabalho realizou uma avaliação geral da função cardíaca, da dinâmica celular do $\mathrm{Ca}^{2+}$, dos elementos reguladores do $\mathrm{Ca}^{2+}$ para elucidar o processo disfuncional dos principais componentes responsáveis pelo equilíbrio do $\mathrm{Ca}^{2+}$ e sua influência na função cardíaca na IC induzida por estenose aórtica.

Neste estudo, a estenose aórtica promoveu mudanças estruturais e disfunção ventricular, tanto diastólica quanto sistólica, como avaliado no ecocardiograma; resultados similares a estudos anteriores. ${ }^{14,15,17,29-33}$ Animais com $\mathrm{EaO}$ desenvolveram hipertrofia concêntrica do ventrículo esquerdo e dilatação do átrio esquerdo, características marcantes neste modelo experimental de sobrecarga de pressão cardíaca. 1,14,15,17,29-33 Com base na Lei de Laplace (Estresse $=$ Pressão $\times$ Raio/2 $\times$ Espessura), o aumento na espessura relativa da parede ventricular esquerda teve como intenção normalizar o estresse parietal sistólico devido à

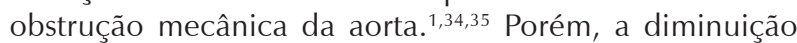
da função sistólica sugere que mesmo após o processo de hipertrofia e o estresse parietal sistólico normalizado, a redução da capacidade contrátil foi responsável pela queda no desempenho sistólico. A função mecânica dos músculos papilares e dos cardiomiócitos reproduziu respostas similares ao exame ecocardiográfico. Animais com EaO apresentaram redução e menos habilidade de desenvolver força ( $\downarrow T D$ e $+\mathrm{tD} / \mathrm{td})$, encurtar $\left(\downarrow \mathrm{VME}\right.$ e $\left.\uparrow \mathrm{TE}_{50 \%}\right)$ e relaxar $\left(\uparrow T R\right.$ e $\left.\mathrm{TR}_{50 \%}\right)$. Este dano funcional ao músculo papilar isolado no estágio tardio da estenose aórtica está de acordo com nosso estudo anterior, que avaliou a doença cardíaca seis semanas após cirurgia. ${ }^{16}$ Além disso, de acordo com os resultados dos cardiomiócitos isolados, os dados da literatura mostram que há uma redução na velocidade de encurtamento dos cardiomiócitos. ${ }^{18} \mathrm{Em}$ nossos animais, a queda cardíaca funcional resultou em IC, expressa pelos seguintes sinais clínicos e patológicos: padrão de respiração alterado, ascite, efusão pleural e trombo em átrio.

Neste modelo experimental, o processo patológico do remodelamento patológico pode induzir um déficit de oxigênio como ponto de partida. A rarefação capilar do miocárdio, ${ }^{22}$ produto da hipertrofia da parede ventricular, pode representar a origem da patologia. Vários mecanismos 


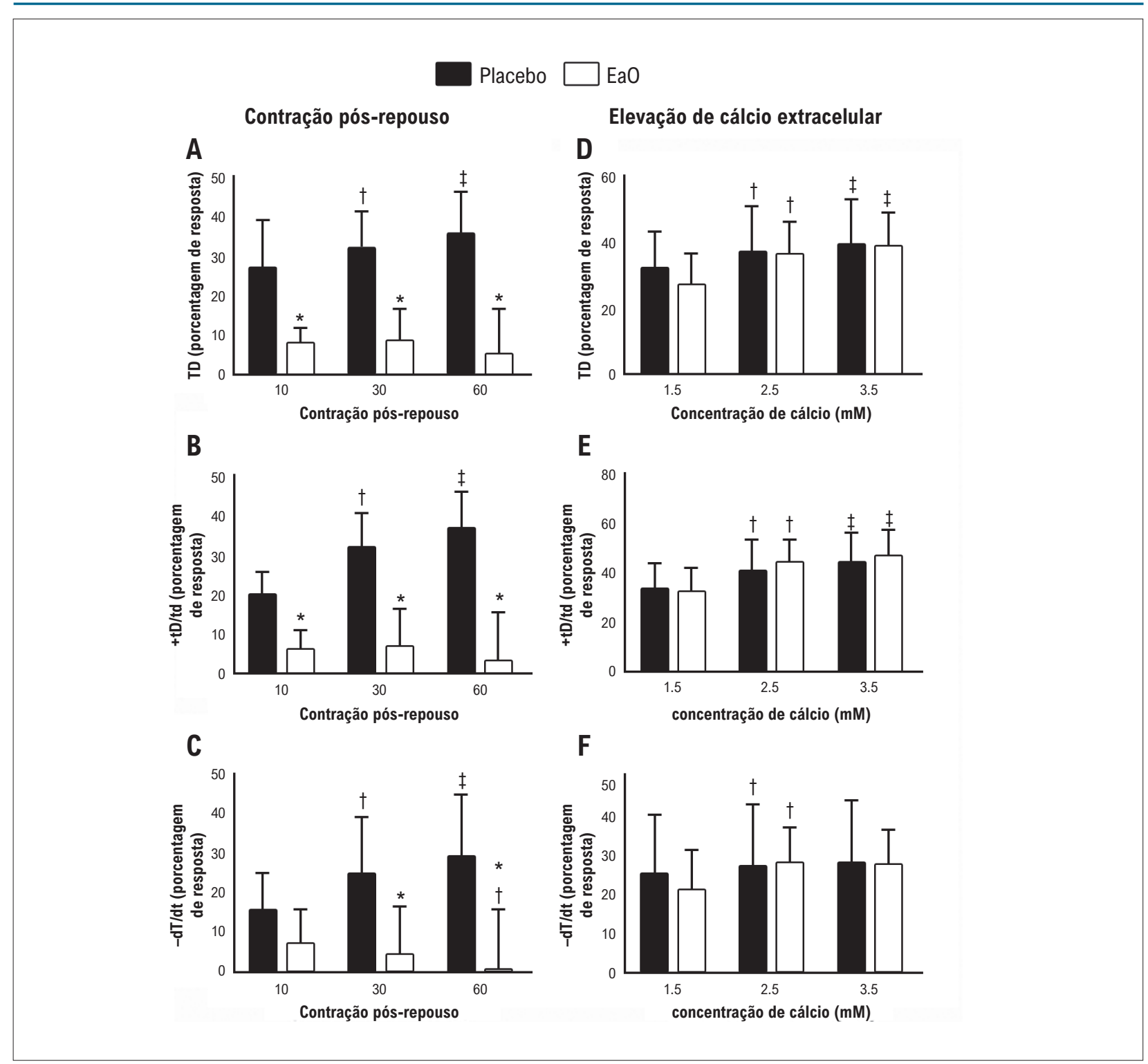

Figura 1 - Porcentagem de resposta à contração pós-repouso (1A, B e C) e elevação da concentração de cálcio extracelular (1D, E e F) desde a base (concentração de $\mathrm{Ca}^{2+}:$ 0,5 mM). TD: pico de tensão desenvolvida; +tD/td: taxa máxima de tensão desenvolvida; -tD/td: taxa máxima do declínio da tensão. Os dados são expressos como media $\pm D P$ da porcentagem da manobra de resposta. Placebo: animais submetidos à cirurgia simulada ( $n=22)$. EaO: animais submetidos à cirurgia de estenose aórtica $(n=12)$. Análise de variância para medidas repetidas e teste post-hoc de Bonferroni. * $p<0,05$ vs. Placebo; $t p<$ 0,05 vs. 10 segundos; $\neq p<0.05$ vs. 10 segundos e 30 segundos $(1 A-C) ; t p<0,05$ vs. 1,5 $\mathrm{Ca}^{2+} ; \neq p<0,05$ vs. 1,5 e 2,5 Ca ${ }^{2+}(1 D-F)$.

podem ser estabelecidos e hiperativados para reajustar o padrão estrutural e funcional do coração, incluindo tônus simpático, o sistema renina-angiotensina-aldosterona, mediadores inflamatórios, estresse oxidativo e a regulação da expressão do gene do miocárdio via microRNAs. ${ }^{36-38}$ Porém, a ativação não harmônica desses microssistemas devido às demandas cardíacas e corporais gera diversas respostas fisiopatológicas, incluindo danos ao manejo do cálcio dos cardiomiócitos. ${ }^{1,34-42}$

A incompatibilidade do $\mathrm{Ca}^{2+}$ citosólico em cardiomiócitos é um dos mecanismos chave para o mal funcionamento do coração em resposta a vários tipos de lesão. 1,4,39 Em modelos de IC, incluindo a estenose aórtica experimental, pesquisadores caracterizaram mudanças na expressão e função transmembrana, assim como proteínas intracelulares que regulam o trânsito de cálcio. ${ }^{18,20,21,43}$ Neste estudo, o aumento de SERCA2a e na expressão da proteína NCX podem trazer uma resposta adaptativa para reduzir ou evitar a sobrecarga do $\mathrm{Ca}^{2+}$ citosólico no fim da diástole. Esta resposta foi parcialmente eficiente, já que houve prejuízo de tempo para a queda do cálcio citosólico nos cardiomiócitos isolados; além disso, mesmo com o padrão compensatório molecular, o prejuízo funcional diastólico foi verificado em um tempo de relaxamento 50\% menor $\left(\mathrm{TR}_{50 \%}\right)$. Como neste estudo, a literatura mostra um 


\section{Placebo $\square$ EaO \\ Bloqueio por ácido ciclopiazônico Bloqueio por diltiazem}

A

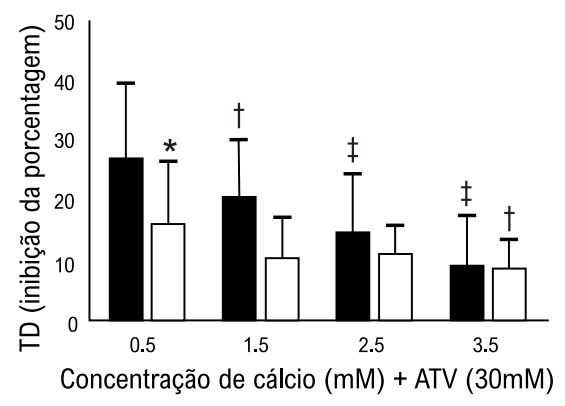

B

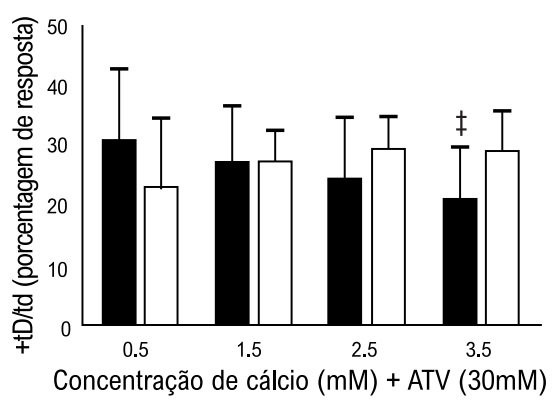

C

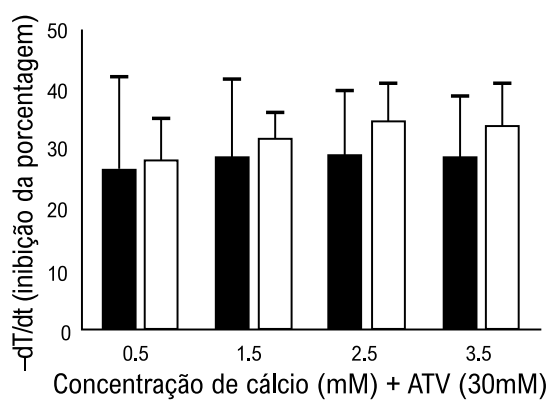

D

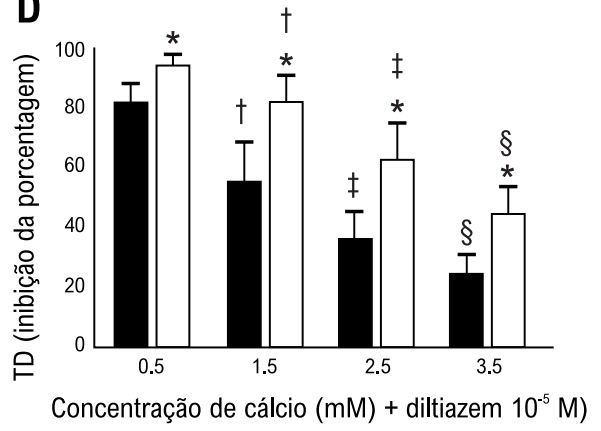

C

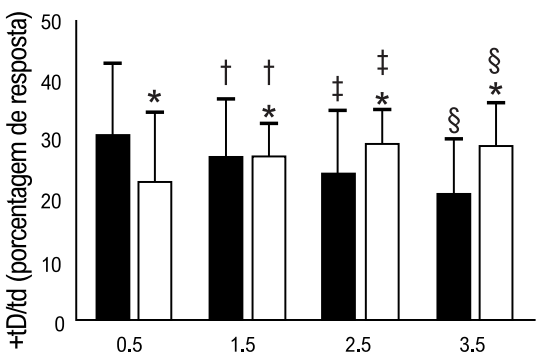

Concentração de cálcio $(\mathrm{mM})+$ diltiazem $\left.10^{-5} \mathrm{M}\right)$

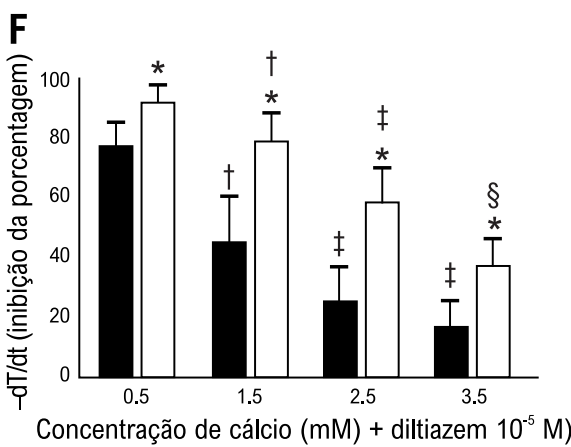

Figura 2 - Inibição da porcentagem de TD (pico de tensão desenvolvida), +dT/dt (taxa máxima de tensão desenvolvida) e -tD/td: taxa máxima do declínio da tensão para ácido ciclopiazônico (bloqueador de SERCA2a; figura $2 A, B$ e C) e diltiazem (bloqueador dos canais de cálcio do tipo L); figura 2D, E e F) mais a concentração incremental de cálcio. Dados são expressos como média \pm DP da porcentagem de resposta da manobra. Placebo: animais submetidos à cirurgia simulada ( $n=22)$. EaO: animais submetidos à cirurgia de estenose aórtica $(n=12)$. Análise de variância para medidas repetidas e teste post-hoc de Bonferroni. " $p<0,05$ vs. Sham; $t p<0,05$ vs. 0,5 $\mathrm{Ca}^{2+} ; \neq p<0,05$ vs. 0,5, e 1,5 $\mathrm{Ca}^{2+} ; \S p<0,05$ vs. 0,5, 1,5 e 2.5 Ca ${ }^{2+}$.

aumento na expressão da proteína NCX na IC. (8,44 $^{18}$ Porém, nossos resultados diferem com relação ao SERCA2a, ${ }^{16,17}$ que, em geral, não mudam ou caem neste cenário da patologia. ${ }^{18,44,45}$ É importante observar que a recaptação do $\mathrm{Ca}^{2+}$ pode reduzir a concentração deste íon no retículo sarcoplasmático (RS) com o passar do tempo.

Consequentemente, há uma redução na quantidade disponível para liberação, ${ }^{4,44}$ via Rianodina, durante a sístole no mecanismo de liberação de $\mathrm{Ca}^{2+}$ induzida pelo $\mathrm{Ca}^{2+}$ dos CCTL. Neste estudo, observamos a expressão de proteína CCTL aumentada em animais com doença cardíaca. Porém, este processo adaptativo parece ser ineficiente, já que os cardiomiócitos dos animais tornaram mais lento o tempo para atingir o pico de $\mathrm{Ca}^{2+}$, com consequente redução da velocidade máxima de encurtamento e aumento no tempo para atingir 50\% do encurtamento. De acordo com a discussão anterior, Szymanska et al. ${ }^{12}$ propuseram que na IC causada pela EaO há mudanças tanto na captação quanto na liberação do $\mathrm{Ca}^{2+}$ pelo RS, e que esses fatores podem contribuir para a deterioração da contração e relaxamento cardíaco.

As manobras no ensaio do músculo papilar isolado foram realizadas para verificar o dano fisiológico de dois dos principais elementos da dinâmica do $\mathrm{Ca}^{2+}$ neste processo patológico, 

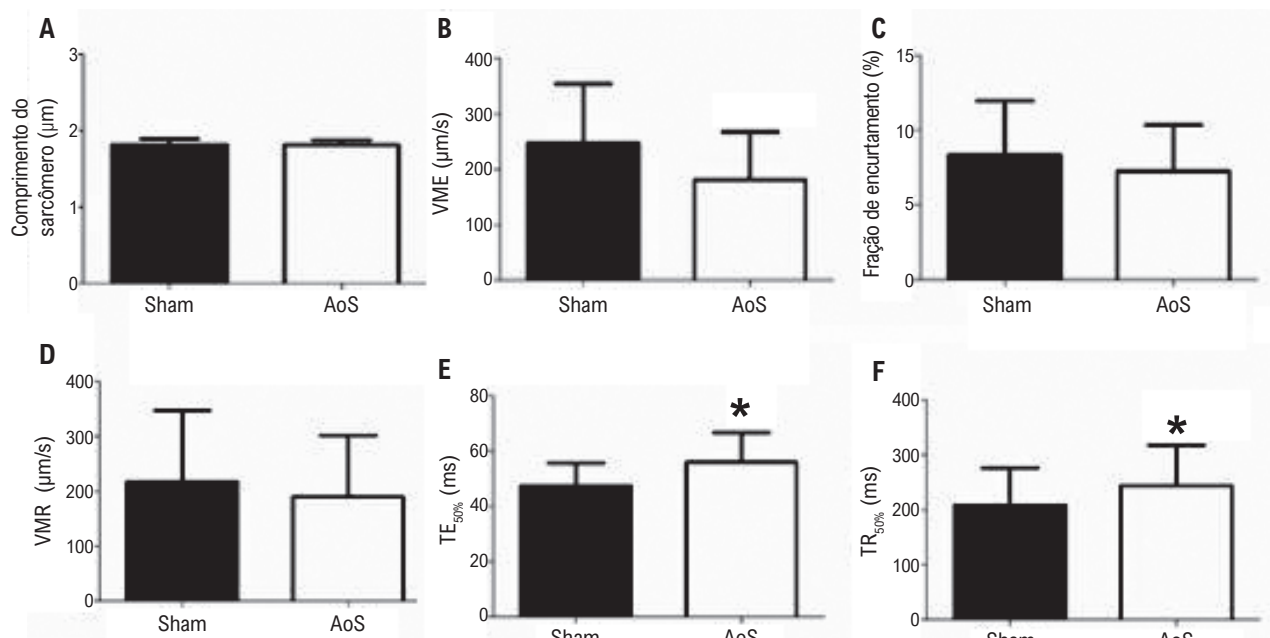

E
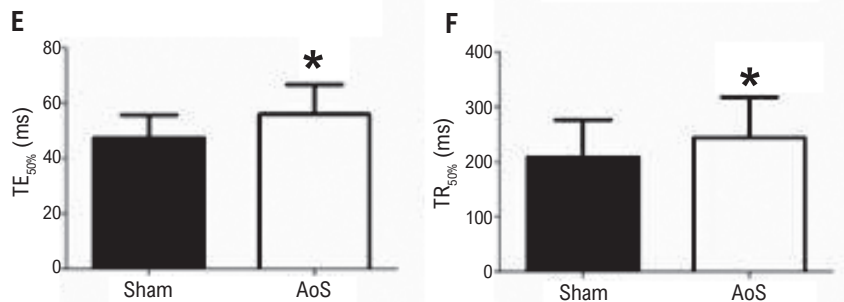

G

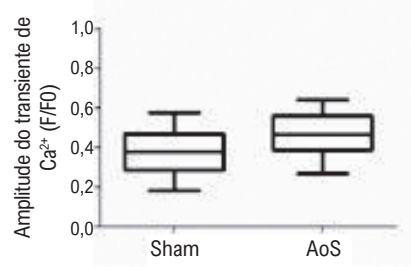

H
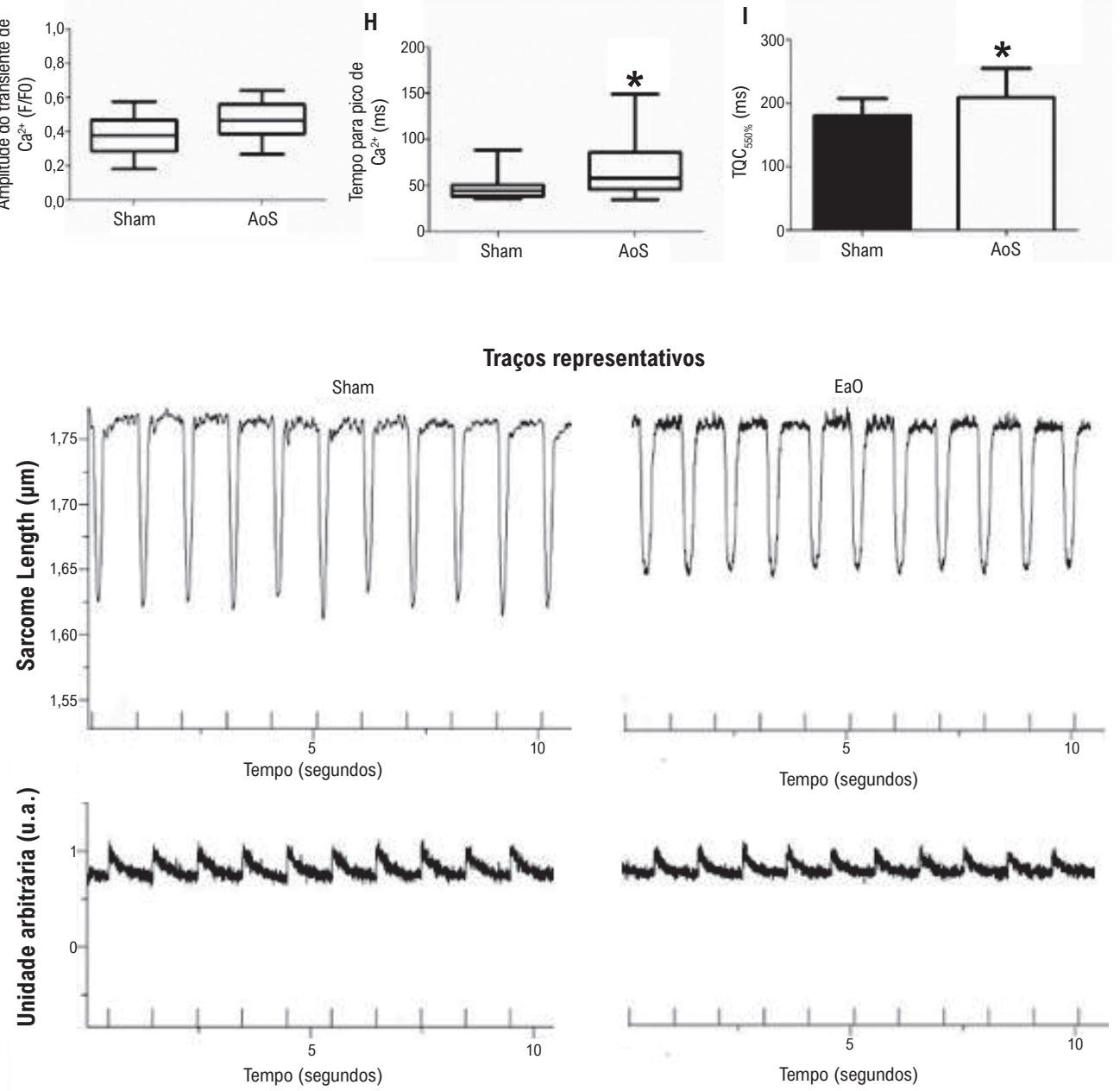

Figura 3 - A função mecânica dos cardiomiócitos e o manejo do cálcio do cardiomiócito. VME: velocidade máxima de encurtamento; VMR: velocidade máxima de relaxamento; $T E_{50 \%}$ : tempo para $50 \%$ de encurtamento; $T R_{50 \%}$ : tempo para $50 \%$ de relaxamento; $T Q C_{50 \%}$ : Tempo para $50 \%$ de queda do Ca ${ }^{2+}$. Dados são expressos como média $\pm D P$, ou mediana (percentil 25; percentil 75). Placebo: animais submetidos à cirurgia simulada ( $n=6$; número de células: 36); EaO: animais submetidos à cirurgia de estenose aórtica ( $n=6$; número de células $=36)$. Teste $t$ de Student. ${ }^{*} p<0,05$. 

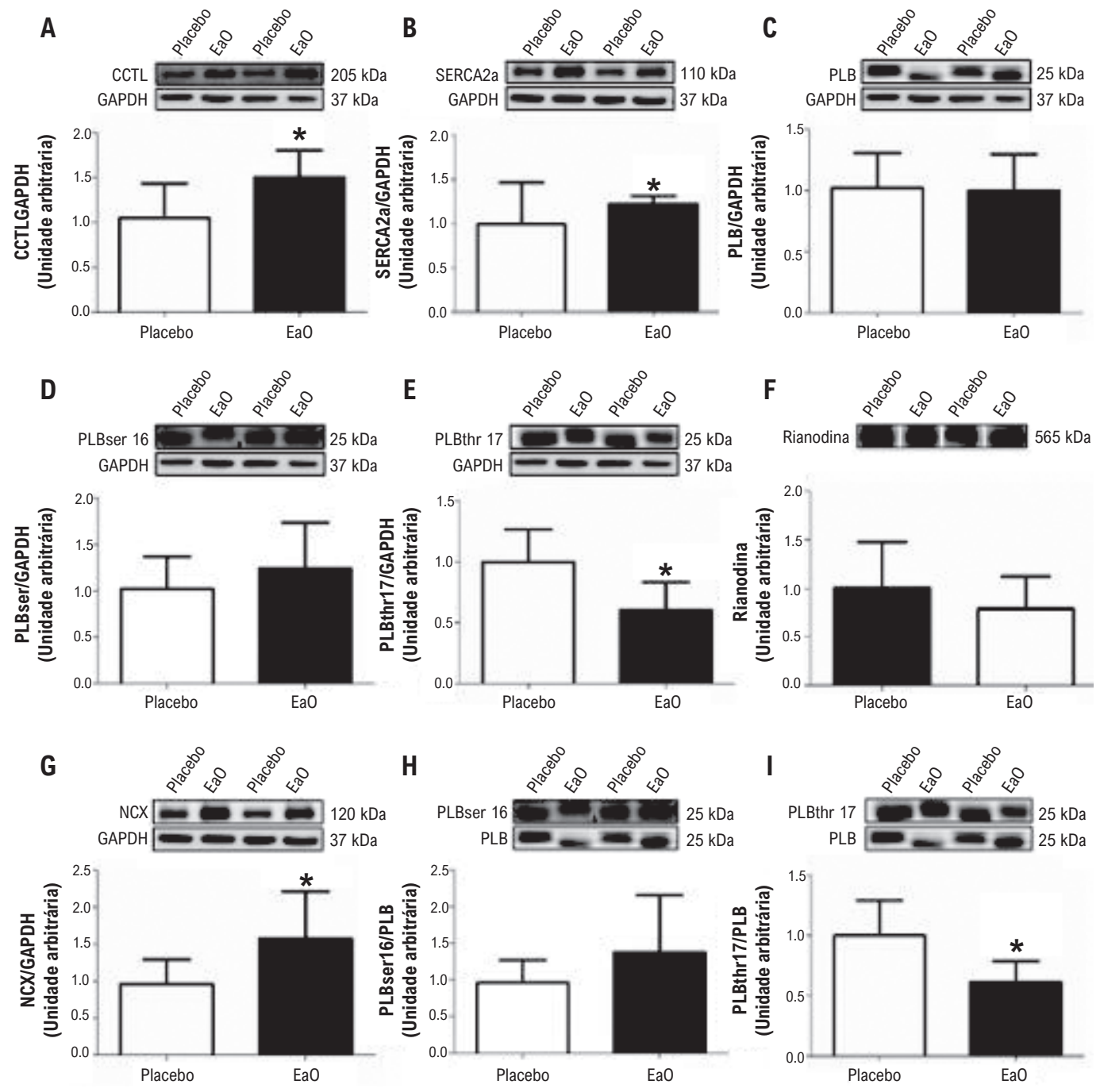

Figura 4 - Expressão da proteína de manejo de cálcio. Dados são expressos como média \pm DP. Placebo: animais submetidos à cirurgia simulada (n=7); EaO: animais submetidos à cirurgia de estenose aórtica ( $n=7)$. CCLT: canais de cálcio do tipo L; SERCA2a: retículo sarco/endoplasmático de Ca ${ }^{2+}$; PLB: Fosfolamban; $P L B_{\text {ser16: }}$ fosfolambam fosforilada em serina 16; PLB $B_{\text {thr17 }}$ fosfolambam fosforilada em treonina 17; NCX: antiportador Na+/Ca2+. Rianodina é expressa sem normalização. Teste $t$ de Student. ${ }^{*} p<0.05$.

SERCA2a e CCTL. O bloqueio do ácido ciclopiazônico e a potenciação pós-pausa foram utilizados para avaliar o potencial para recaptação do $\mathrm{Ca}^{2+} \mathrm{e}$ a capacidade funcional de SERCA2a. Havia uma diferença na resposta entre as manobras para analisar a função de SERCA2a. A contração pós-repouso mostrou que o potencial para a recaptação do $\mathrm{Ca}^{2+}$ foi prejudicado pela estenose aórtica. Porém, após o bloqueio de SERCA2a devido ao ácido ciclopiazônico, os grupos placebo e EaO mostraram respostas similares às variáveis analisadas. Considerando que os animais com a cardiopatia demonstraram maior expressão da referida proteína, a porcentagem do bloqueio deve ter sido mais alta no grupo placebo, por ter menor quantidade de SERCA2a do que o grupo EaO. Porém, como o número de proteínas não bloqueadas no grupo EaO foi maior do que no grupo placebo, é possível considerar que este grupo remanescente de SERCA2a pós-bloqueio em animais com $\mathrm{EaO}$ demonstrou dano funcional.

Nossos dados estão de acordo com estudos anteriores, que sugerem a estenose aórtica como sendo indutor da deterioração funcional de SERCA2a. ${ }^{11,12,16}$ Além disso, nossos achados mostram que a expressão aumentada de SERCA2a, o principal mantenedor da homeostase citosólica de $\mathrm{Ca}^{2+}$, não foi suficiente para compensar pela redução na atividade intrínseca desta proteína; esta hipótese é reforçada pelo resultados deste estudo, que demonstraram tempo reduzido para atingir 50\% da queda do cálcio em cardiomiócitos. Como SERCA2a é uma ATPase, sob condições de baixa adenosina trifosfato (ATP), a atividade 
intrínseca desta proteína poderia ser prejudicada, causando disfunção na recaptação do $\mathrm{Ca}^{2+}$ pelo $\mathrm{RS} .{ }^{45} \mathrm{Em}$ favor desta hipótese, um estudo prévio feito pelo nosso grupo (esses resultados não estão publicados) mostrou que animais com EaO, duas semanas após cirurgia, apresentaram aumento no fator induzido por hipoxia-1 (HIF-1 a), indicador mais importante do déficit de oxigênio tecidual, que pode indicar uma redução na produção de ATP.

Além das alterações mencionadas anteriormente, este estudo identificou uma redução na forforilação de fosfolambam em treonina 17, sugerindo que o prejuízo da recaptação de $\mathrm{Ca}^{2+}$ pode não só ser atribuído ao prejuízo funcional intrínseco de SERCA2a, mas também ao maior bloqueio desta proteína pela fosfolambam.

O bloqueio de diltiazem e a elevação de $\mathrm{Ca}^{2+}$ extracelular no músculo papilar mostrou que animais com doença cardíaca tinham a função CCTL prejudicada. Embora tenha havido um aumento na expressão de proteína desses canais, houve um aumento no tempo para alcançar o pico de $\mathrm{Ca}^{2+}$ em cardiomiócitos isolados, uma redução na VME e aumento no $\mathrm{TE}_{50 \%}$. Esses achados estão de acordo com os resultados da literatura, que mostram que o prejuízo cardíaco por EaO geram uma variante de splicing fetal $\left(\mathrm{Ca}_{\mathrm{v}} 1.2_{\mathrm{e} 21+22}\right)$ que reduz a expressão e a atividade desses canais, e que aumenta a ubiquitinação de CCTL via degradação proteossomal. ${ }^{21}$ Além disso, no remodelamento patológico pela $\mathrm{EaO}$ juntamente à redução de $\mathrm{I}_{\mathrm{Ca}^{\prime}}$ há ineficiência no acoplamento de CCTLs com receptores Rianodina, tanto devido à degradação de túbulos $T$ quanto pela redução de junctofilina-2, a proteína responsável por ancorar o retículo sarcoplasmático à membrana celular. ${ }^{20}$

\section{Limitações do estudo}

Neste estudo, os cardiomiócitos não foram isolados somente no ventrículo esquerdo. Então, os resultados dos cardiomiócitos tanto dos ventrículos esquerdo como direito foram avaliados e discutidos. É importante enfatizar que um entendimento adequado da fisiologia cardíaca em estudos celulares requer conhecimento sobre a contratilidade ventricular, já que os ventrículos direito e esquerdo têm propriedades funcionais distintas. Assim, também seria relevante realizar uma análise molecular em ambos os ventrículos; porém, a expressão das proteínas do trânsito de cálcio apenas foi realizada no VE.

\section{Referências}

1. Katz AM. Heart Failure. In: Katz AM, editor. Physiology of the Heart. 5th ed. Philadelphia: Lippincott Williams \& Wilkins; 2011. p. 510-47.

2. Opie LH. Myocardial Contraction and Relaxation. In: Opie LH, editor. The Heart. Physiology from Cell to Circulation. 3rd ed. Philadelphia: Lippincott-Raven; 1998. p. 209-31.

3. Burchfield JS, Xie M, Hill JA. Pathological Ventricular Remodeling: Mechanisms: Part 1 of 2. Circulation. 2013;128(4):388-400. doi: 10.1161/ CIRCULATIONAHA.113.001878.

4. Nabeebaccus A, Sag CA, Webb I, Shah AM. Cellular Basis for Heart Failure. In: Mann DL, Felker GM, editors. Heart Failure: A Companion to Braunwald's Heart Disease. 3rd ed. Amsterdam: Saunders; 2016. p. 28-41.

\section{Conclusões}

Nosso estudo buscou esclarecer e facilitar o entendimento sobre os eventos fisiopatológicos do trânsito de cálcio e sobre as mudanças em seus agentes reguladores principais no processo patológico cardíaco causado pela estenose aórtica. De acordo com nossos resultados, neste modelo experimental de IC, há mudanças relevantes na dinâmica do cálcio devido a alterações na expressão de NCX e SERCA2a, na expressão da proteína do CCTL, e redução da fosforilação do resíduo Thr(17) de PLB. Além disso, o dano funcional da SERCA2a e do CCTL foram essenciais para a deterioração contrátil e do relaxamento. Assim, é importante desenvolver tratamentos que foquem não só em SERCA2a e CCTL, mas também no entendimento de todos os processos patológicos para reequilibrar o fluxo do cálcio intracelular e a função cardíaca.

\section{Contribuição dos autores}

Concepção e desenho da pesquisa: Silva VL, Campos DHS, Leopoldo A, Cicogna AC; Obtenção de dados: Silva VL, Souza SLB, Mota GAF, Campos DHS, Melo AB, Vileigas DF, Coelho PM, Sant'Ana PG, Bazan SGZ, Leopoldo A, Cicogna AC; Análise e interpretação dos dados: Silva VL, Souza SLB, Mota GAF, Campos DHS, Sant'Ana PG, Bazan SGZ, Leopoldo A, Cicogna AC; Análise estatística: Silva VL, Melo AB, Vileigas DF, Coelho PM, Leopoldo A, Cicogna AC; Obtenção de financiamento: Silva VL, Campos DHS, Cicogna AC; Redação do manuscrito: Silva VL, Souza SLB, Mota GAF, Melo AB, Cicogna AC; Revisão crítica do manuscrito quanto ao conteúdo intelectual importante: Silva VL, Souza SLB, Mota GAF, Cicogna AC.

\section{Potencial conflito de interesse}

Não há conflito com o presente artigo

\section{Fontes de financiamento}

O presente estudo foi financiado pela FAPESP (2015/20013-5).

\section{Vinculação acadêmica}

Este artigo é parte de tese de doutorado de Vitor Loureiro da Silva pela Universidade de São Paulo.
5. BersDM, EisnerDA, Valdivia HH. Sarcoplasmic Reticulum Ca2+ and HeartFailure: Roles of Diastolic Leak and Ca2 + Transport. Circ Res. 2003;93(6):487-90. doi: 10.1161/01.RES.0000091871.54907.6B.

6. Roos KP, Jordan MC, Fishbein MC, Ritter MR, Friedlander M, Chang HC, et al. Hypertrophy and HeartFailure in MiceOverexpressingtheCardiacSodium-Calcium Exchanger.JCard Fail. 2007;13(4):318-29. doi: 10.1016/j.cardfail.2007.01.004.

7. Høydal MA, Kirkeby-Garstad I, Karevold A, Wiseth R, Haaverstad R, Wahba A, et al. Human Cardiomyocyte Calcium Handling and Transverse Tubules in Mid-Stage of Post-Myocardial-Infarction Heart Failure. ESC Heart Fail. 2018;5(3):332-42. doi: 10.1002/ehf2.12271.

8. Bing OH, Brooks WW, Conrad CH, Sen S, Perreault CL, Morgan JP. Intracellular Calcium Transients in Myocardium from Spontaneously Hypertensive Rats During the Transition to Heart Failure. Circ Res. 1991;68(5):1390-400. 
9. Mishra S, Sabbah HN, Rastogi S, Imai M, Gupta RC. Reduced Sarcoplasmic Reticulum Ca2 + Uptake and Increased $\mathrm{Na}$ +-Ca2 + Exchanger Expression in Left Ventricle Myocardium of Dogs with Progression of Heart Failure. Heart Vessels. 2005;20(1):23-32. doi: 10.1007/s00380-004-0792-6.

10. Mørk HK, Sjaastad I, Sejersted OM, Louch WE. Slowing of Cardiomyocyte $\mathrm{Ca} 2+$ Release and Contraction During Heart Failure Progression in Postinfarction Mice. Am J Physiol Heart Circ Physiol. 2009;296(4):1069-79. doi: 10.1152/ajpheart.01009.2008.

11. Schouten VJ, Vliegen HW, van der Laarse A, Huysmans HA. Altered Calcium Handling at Normal Contractility in Hypertrophied Rat Heart. J Mol Cell Cardiol. 1990;22(9):987-98. doi: 10.1016/0022-2828(90)91038-9.

12. Szymanska G, Strömer H, Kim DH, Lorell BH, Morgan JP. Dynamic Changes in Sarcoplasmic Reticulum Function in Cardiac Hypertrophy and Failure. Pflugers Arch. 2000;439(3):339-48. doi: 10.1007/s004249900097.

13. Wang Z, Nolan B, Kutschke W, Hill JA. Na+-Ca2+ Exchanger Remodeling in Pressure Overload Cardiac Hypertrophy. J Biol Chem. 2001;276(21):1770611. doi: $10.1074 /$ jbc.M100544200.

14. Souza SLB, Mota GAF, Silva VL, Sant'Ana PG, Vileigas DF, Campos DHS, et al. Adjustments in $\beta$-Adrenergic Signaling Contribute to the Amelioration of Cardiac Dysfunction by Exercise Training in Supravalvular Aortic Stenosis. Cell Physiol Biochem. 2020;54(4):665-81. doi: 10.33594/000000247.

15. Mota GAF, Souza SLB, Silva VL, Gatto M, Campos DHS, Sant'Ana PG, et al. Cardioprotection Generated by Aerobic Exercise Training is not Related to the Proliferation of Cardiomyocytes and Angiotensin-(1-7) Levels in the Hearts of Rats with Supravalvar Aortic Stenosis. Cell Physiol Biochem. 2020;54(4):719-35. doi: 10.33594/000000251.

16. Silveira CFSMP, Campos DHS, Freire PP, Deus AF, Okoshi K, Padovani CR, et al. Importance of SERCA2a on Early Isolated Diastolic Dysfunction Induced by Supravalvular Aortic Stenosis in Rats. Braz J Med Biol Res. 2017;50(5):5742. doi: 10.1590/1414-431X20175742.

17. De Tomasi LC, Campos DHS, Sant'Ana PG, Okoshi K, Padovani CR, Murata GM, et al. Pathological Hypertrophy and Cardiac Dysfunction are Linked to Aberrant Endogenous Unsaturated Fatty Acid Metabolism. PLoS One. 2018;13(3):0193553. doi: 10.1371/journal.pone.0193553.

18. Hiemstra JA, Veteto AB, Lambert MD, Olver TD, Ferguson BS, McDonald KS, et al. Chronic Low-Intensity Exercise Attenuates Cardiomyocyte Contractile Dysfunction and Impaired Adrenergic Responsiveness in AorticBanded Mini-Swine. J Appl Physiol. 2018;124(4):1034-44. doi: 10.1152/ japplphysiol.00840.2017.

19. Lu YM, Huang J, Shioda N, Fukunaga K, Shirasaki Y, Li XM, et al. CaMKIIIB Mediates Aberrant NCX1 Expression and the Imbalance of NCX1/SERCA in Transverse Aortic Constriction-Induced Failing Heart. PLoS One. 2011;6(9):24724. doi: 10.1371/journal.pone.0024724.

20. Xu M, Zhou P, Xu SM, Liu Y, Feng X, Bai SH, et al. Intermolecular Failure of L-type Ca2+ Channel and Ryanodine Receptor Signaling in Hypertrophy. PLoS Biol. 2007;5(2):21. doi: 10.1371/journal.pbio.0050021.

21. Hu Z, Wang JW, Yu D, Soon JL, de Kleijn DP, Foo R, et al. Aberrant Splicing Promotes Proteasomal Degradation of L-type CaV1.2 Calcium Channels by Competitive Binding for CaV $\beta$ Subunits in Cardiac Hypertrophy. Sci Rep. 2016;6:35247. doi: 10.1038/srep35247.

22. van Deel ED, de Boer M, Kuster DW, Boontje NM, Holemans P, Sipido KR, et al. Exercise Training Does Not Improve Cardiac Function in Compensated or Decompensated Left Ventricular Hypertrophy Induced by Aortic Stenosis. J Mol Cell Cardiol. 2011;50(6):1017-25. doi: 10.1016/j.yjmcc.2011.01.016.

23. Bentivegna LA, Ablin LW, Kihara Y, Morgan JP. Altered Calcium Handling in Left Ventricular Pressure-Overload Hypertrophy as Detected with Aequorin in the Isolated, Perfused Ferret Heart. Circ Res. 1991;69(6):1538-45. doi: 10.1161/01.res.69.6.1538.

24. van Deel ED, Octavia Y, de Waard MC, de Boer M, Duncker DJ. Exercise Training has Contrasting Effects in Myocardial Infarction and Pressure Overload Due to Divergent Endothelial Nitric Oxide Synthase Regulation. Int J Mol Sci. 2018:19(7):1968. doi: 10.3390/ijms19071968.
25. Vileigas DF, Harman VM, Freire PP, Marciano CLC, Sant'Ana PG, Souza SLB, et al. Landscape of Heart Proteome Changes in a Diet-Induced Obesity Model. Sci Rep. 2019;9(1):18050. doi: 10.1038/s41598-01954522-2.

26. Bregagnollo EA, Zornoff LA, Okoshi K, Sugizaki M, Mestrinel MA Padovani CR, ET AL. Myocardial Contractile Dysfunction Contributes to the Development of Heart Failure in Rats with Aortic Stenosis. Int Cardiol. 2007;117(1):109-14. doi: 10.1016/j.ijcard.2006.06.006.

27. Louch WE, Sheehan KA, Wolska BM. Methods in Cardiomyocyte Isolation, Culture, and Gene Transfer. J Mol Cell Cardiol. 2011;51(3):28898. doi: 10.1016/j.yjmcc.2011.06.012.

28. Charan J, Biswas T. How to Calculate Sample Size for Different Study Designs in Medical Research? Indian J Psychol Med. 2013;35(2):121-6. doi: 10.4103/0253-7176.116232.

29. Pacagnelli FL, Okoshi K, Campos DHS, Souza RWA, Padovani CR, Carvalho RF, et al. Physical Training Attenuates Cardiac Remodeling in Rats with Supra-Aortic Stenosis. J. Clin. Exp. Cardiol. 2014;20(8):1-17.

30. Gomes MJ, Martinez PF, Campos DH, Pagan LU, Bonomo C, Lima AR, et al. Beneficial Effects of Physical Exercise on Functional Capacity and Skeletal Muscle Oxidative Stress in Rats with Aortic Stenosis-Induced Heart Failure. Oxid Med Cell Longev. 2016;2016:8695716. doi: $10.1155 / 2016 / 8695716$

31. Souza RW, Fernandez GJ, Cunha JP, Piedade WP, Soares LC, Souza PA, et al. Regulation of Cardiac microRNAs Induced by Aerobic Exercise Training During Heart Failure. Am J Physiol Heart Circ Physiol. 2015;309(10):1629-41. doi: 10.1152/ajpheart.00941.2014.

32. Souza PA, Souza RW, Soares LC, Piedade WP, Campos DH, Carvalho RF, et al. Aerobic Training Attenuates Nicotinic Acethylcholine Receptor Changes in the Diaphragm Muscle During Heart Failure. Histol Histopathol. 2015;30(7):801-11. doi: 10.14670/HH-11-581.

33. Souza RW, Piedade WP, Soares LC, Souza PA, Aguiar AF, Vechetti-Júnior IJ, et al. Aerobic Exercise Training Prevents Heart Failure-Induced Skeletal Muscle Atrophy by Anti-Catabolic, but not Anabolic Actions. PLoS One. 2014;9(10):e110020. doi: 10.1371/journal.pone.0110020.

34. Plitt GD, Spring JT, Moulton MJ, Agrawal DK. Mechanisms, Diagnosis, and Treatment of Heart Failure with Preserved Ejection Fraction and Diastolic Dysfunction. Expert Rev Cardiovasc Ther. 2018;16(8):579-89. doi: 10.1080/14779072.2018.1497485.

35. Nakamura M, Sadoshima J. Mechanisms of Physiological and Pathological Cardiac Hypertrophy. Nat Rev Cardiol. 2018;15(7):387-407. doi: 10.1038/s41569-018-0007-y.

36. Diwan A, Hill JA, Force TL. Molecular Basis for Heart Failure. In: Mann DL, Felker GM, editors. Heart Failure: A Companion to Braunwald's Heart Disease. 3rd ed. Amsterdam: Saunders; 2016. p. 1-27.

37. Schirone L, Forte M, Palmerio S, Yee D, Nocella C, Angelini F, et al. A Review of the Molecular Mechanisms Underlying the Development and Progression of Cardiac Remodeling. Oxid Med Cell Longev. 2017; 2017:3920195. doi: 10.1155/2017/3920195.

38. Maillet M, van Berlo JH, Molkentin JD. Molecular Basis of Physiological Heart Growth: Fundamental Concepts and New Players. Nat Rev Mol Cell Biol. 2013;14(1):38-48. doi: 10.1038/nrm3495.

39. Mann DL. Pathophysiology of Heart Failure. In: Mann DL, Zipes DP, Libby P, editors. Braunwald's Heart Disease: A Textbook of Cardiovascular Medicine. Amsterdam: Saunders; 2012. p. 487-504.

40. van Heerebeek L, Paulus WJ. Alterations in Ventricular Function: Diastolic Heart Failure. In: Mann DL, Felker GM, editors. Heart Failure: A Companion to Braunwald's Heart Disease. 3rd ed. Amsterdam: Saunders; 2016. p. 156-76

41. Gu J, Zhao F, Wang Y, Gao J, Wang X, Xue J, et al. The Molecula Mechanism of Diastolic Heart Failure. Integr Med Int. 2015;2:143-8. doi: $10.1159 / 000441223$. 
Silva et al.

Dinâmica do Cálcio na Hipertrofia Descompensada

Artigo Original

42. Souders CA, Borg TK, Banerjee I, Baudino TA. Pressure Overload Induces Early Morphological Changes in the Heart. Am J Pathol. 2012;181(4):1226-35. doi: 10.1016/j.ajpath.2012.06.015.

43. Maki T, Gruver EJ, Davidoff AJ, Izzo N, Toupin D, Colucci W, et al. Regulation of Calcium Channel Expression in Neonatal Myocytes by Catecholamines. J Clin Invest. 1996;97(3):656-63. doi: 10.1172/JCl118462.
44. Hasenfuss G, Mann DL. Pathophysiology of Heart Failure. In: Libby P, Zipes DP, Bonow RO, MannDL, TomaselliGF, editors. Braunwald's HeartDisease:A Textbook of Cardiovascular Medicine. 11th ed. Amsterdam: Elsevier; 2019. p. 442-460.

45. Periasamy M, Bhupathy P, Babu GJ. Regulation of Sarcoplasmic Reticulum Ca2+ ATPase Pump Expression and its Relevance to Cardiac Muscle Physiology and Pathology. Cardiovasc Res. 2008;77(2):265-73. doi: 10.1093/cvr/cvm056. 